\title{
The Study of the Solid Polymer Electrolyte Oxygen Concentrator with Nanostructural Catalysts Based on Hydrophobized Support
}

\author{
A. S. Pushkarev ${ }^{a, b, c, *}$, I. V. Pushkareva ${ }^{a, b}$, M. A. Solovyev ${ }^{a, b}$, S. I. Butrim ${ }^{b}$, and S. A. Grigoriev ${ }^{a}$ \\ a National Research Center "Kurchatov Institute”, Moscow, 123182 Russia \\ ${ }^{b}$ National Research University "Moscow Power Engineering Institute”, Moscow, 111250 Russia \\ ${ }^{c}$ Moscow Institute of Physics and Technology (National Research University), Dolgoprudnyi, Moscow oblast, 141700 Russia \\ *e-mail: pushkarev_as@nrcki.ru \\ Received June 11, 2020; revised June 11, 2020; accepted July 3, 2020
}

\begin{abstract}
The efficient production of gaseous oxygen used in many branches of industry to provide human life in anaerobic environments and in medicine (e.g., in the case of acute respiratory failure as one of COVID-19 complications) is challenging nowadays. The electrochemical oxygen pump (concentrator) with a solid polymer electrolyte representing an electrolyzer with air cathode depolarization is a very promising device, which provides the portable, safe, and efficient in situ production of highly pure oxygen at a twice lower energy consumption as compared to the water electrolyzer with a solid polymer electrolyte. The effect produced by the hydrophobization of a nanostructured oxygen reduction catalyst on the oxygen pump characteristics and the endurance of a cathode catalytic layer to flooding has been considered. The modification of a carbon support with polytetrafluoroethylene particles improves the removal of excessive water from the catalytic layer and increases the limiting current characterizing the appearance of transport limitations. The operational parameters (air temperature, flow rate, and pressure) also have an essential effect on the oxygen pump performance and must be optimized to improve water transport in catalytic layers, increase the operating current densities, and reduce the energy consumption in oxygen production.
\end{abstract}

DOI: $10.1134 / \mathrm{S} 1995078020060154$

\section{INTRODUCTION}

Among electrochemical systems with a solid polymer electrolyte (SPE), the most widely used devices are fuel cells (FCs) and water electrolyzers, which are already in the market due to such their properties as high efficiency and flexibility, compactness, and great specific power. In particular, fuel cells are considered as a basis of power stations and power sources for small energy generators (including backup ones), transport vehicles (from small unmanned aerial vehicles to cars, buses, etc.), and portable electronic devices [1], and an electrolyzer is construed as a source of hydrogen and oxygen (which is frequently considered as a byproduct) [2].

However, it is possible to distinguish a number of electrochemical SPE-based devices, which may find their own market niches. In particular, among such devices are the oxygen concentrator [3, 4], the hydrogen concentrator [5], the air dryer [6], the ozone generator [7,8], and the converter of alcohols (methanol, ethanol, etc.) $[9,10]$.

At the present moment, oxygen is generally produced by separating the air components (cryogenic, membrane, and sorption technologies [11]) and by water electrolysis, which is generally used for the production of hydrogen. In view of the increasingly broad propagation of water electrolyzers, oxygen is an important hydrogen energy industry by-product used in different branches of industry to provide human life in anaerobic environments and in medicine (e.g., in the case of acute respiratory failure as one of the COVID-19 complications) [12]. Moreover, it does not contaminate the environment and, on the contrary, has a positive effect on the environmental situation. On the other hand, the energy consumption in its production by this method are rather high (at least twice higher than the energy consumption in the production of hydrogen: $\left.7-10(\mathrm{~kW} \mathrm{~h}) / \mathrm{STPm}^{3}[3,13]\right)$. Among the other shortcomings of SPE electrolyzers in terms of the production of oxygen as a major product is the need for the safe utilization of formed hydrogen and the crossover of hydrogen through a membrane with target product contamination exhibited as rather high hydrogen concentrations in the oxygen formed on the anode (up to $1.5 \mathrm{vol} \%$ depending on the current density, pressure, and some other process parameters $[14,15])$.

For this reason, it is necessary to refuse the cathode hydrogen evolution reaction and provide the con- 
sumption of protons formed in the anode water oxidation process in a different process, e.g., the oxygen reduction reaction (ORR) [16], which is a cathode reaction in SPE fuel cells [17]. Such an approach will also provide an essential decrease in the energy consumption in the production of oxygen, as the equilibrium voltage of such an element is close to zero [4].

The proposed electrochemical system is a SPE oxygen pump (OP) (concentrator), in which oxygen evolution is an anode process, and oxygen reduction with the formation of water is a cathode process, is promising for the efficient production of highly pure oxygen including compression (to $25 \mathrm{MPa}$ ) [18]. Among its advantages is noiseless operation, the absence of substances contaminating the end product in the working zone, high flexibility in loading, and the possibility of using the ambient air as a reagent without preheating [4]. The results of some preliminary studies $[4,16]$ have demonstrated that the formation of hydrogen remains negligible at rather high voltages $(1.7-1.8 \mathrm{~V})$, thus ensuring safety in combination with high productivity for such a concentrator. Let us point out that the traditional methods of oxygen concentration from the air provide oxygen purity of more than 99 vol \% [19], whereas the SPE oxygen concentrator can provide the oxygen purity of up to $99.9 \mathrm{vol} \%$ and higher [16].

Among the most important aspects of SPE electrochemical systems is water balance in a cell. In particular, the slow removal of moisture from the cathode electrocatalytic layer of a SPE fuel cell leads to its flooding with a decrease in its active surface area and, on the contrary, the very fast removal of water, which is supplied from the anode by electroosmotic transfer and additionally formed in the oxygen reduction reaction, leads to the local drying of solid polymer electrolyte and an increase in its resistance with corresponding worsening in cell performance [20]. Moreover, at practically significant current densities $\left(0.5-1 \mathrm{~A} / \mathrm{cm}^{2}\right)$, the air cathode of the SPE oxygen pump is forced to function under the conditions of great electroosmotic and diffusion water flows, which move from the anode and are typical for a water filled SPE water electrolyzer (the number of transferred water molecules per proton attains $2.5-4$ per $\mathrm{H}^{+}$[21]). In this connection, to create a highly efficient SPE oxygen concentrator, it is necessary to optimize its operation regimes and the composition of the cathode and anode electrocatalytic layers from the viewpoint of their activity and water balance of the membrane electrode assembly (MEA).

The submitted paper considers the effect produced by the hydrophobization of a nanostructured carbon support on the endurance of the cathode catalytic layer of an SPE oxygen pump to flooding. The used criterion was the limiting current density (or limiting current) characterizing the transport limitations appearing in the catalytic layer upon its flooding with an excessive amount of water. In addition, the effect of different operational parameters (air temperature, flow rate, and pressure in the cathode chamber) on the performance of the SPE oxygen pump based on a cathode with an optimal polytetrafluoroethylene (PTFE) content has been studied to give some recommendations on the further optimization of SPE oxygen pump operation regimes.

\section{EXPERIMENTAL}

The hydrophobization of a carbon support with PTFE particles was performed via the treatment of Vulcan XC-72 carbon black (Cabot, United States) in a water suspension of DISP 30-250 (FuelCellStore, United States) with a particle size of $0.1-0.15 \mu \mathrm{m}$ on a water bath at a temperature of $100^{\circ} \mathrm{C}$ under continuous stirring until the latter sustained complete coagulation exhibited as suspension decoloration. After the hydrophobizer was precipitated, the support was subjected to triple decantation in bidistilled water, drying, and further annealing at a temperature of $360^{\circ} \mathrm{C}$ for $1 \mathrm{~h}$. After cooling, the support was ground in a Retsch PM-100 ball mill (Retsch, Germany). The described method resulted in the supports with a PTFE content of 5,10 , and $15 \mathrm{wt} \%\left(\mathrm{C}^{5}, \mathrm{C}^{10}\right.$, and $\mathrm{C}^{15}$, respectively).

The synthesis of cathode catalysts on different supports was performed by reducing the precursor of $\mathrm{Pt}$ nanoparticles $\mathrm{H}_{2} \mathrm{PtCl}_{6} \cdot 6 \mathrm{H}_{2} \mathrm{O}$ in an ethyleneglycol medium ("polyol" method) as detailed in [22, 23].

The specific surface area of the modified nanostructured carbon supports was determined by the BET method on a Micromeritics TriStar 3000 analyzer (United States). The specific electrochemically active surface area (EASA) of the catalysts was determined from the cyclic voltammograms measured in a standard three-electrode cell in a deaerated $0.5 \mathrm{M}$ $\mathrm{H}_{2} \mathrm{SO}_{4}$ solution [10, 24].

Nanostructured Ir black used as an anode electrocatalysts was synthesized via the electrochemical reduction of the precursor $\mathrm{H}_{2} \mathrm{IrCl}_{6} \cdot 6 \mathrm{H}_{2} \mathrm{O}$ with the use of $\mathrm{NaBH}_{4}$ as a reducing agent [25].

To study the SPE oxygen pump performance, circle MEAs with a working surface area of $7 \mathrm{~cm}^{2}$ and Nafion ${ }^{\circledR} 117$ membrane (Chemours Company, United States) as a solid polymer electrolyte were manufactured. Porous VT-1-0 titanium (thickness, $900 \mu \mathrm{m}$; porosity, 28\%) $[4,26]$ was used as an anode gas diffusion electrode (GDE), and ELAT LT1400W carbon cloth (NuVant Systems Inc., United States) with a hydrophobic macroporous sublayer and a porosity of $62-64 \%$ was used as a cathode GDE.

The formation of electrocatalytic layers on the GDE surface was carried out by "catalytic ink" sputtering onto it in an air flow with the intermediate dry- 
ing of deposited layers [23, 27]. "Catalytic ink" incorporated an electrocatalysts and a solution of proton exchange polymer Nafion ${ }^{\circledR}$ (Ion Power, United States) (polymer content in dry residue was $15 \mathrm{wt} \%$ in the case of supported Pt nanoparticles and $5 \mathrm{wt} \%$ in the case of Ir black) and were prepared by homogenizing their components in an isopropanol medium in an ultrasonic bath at a frequency of $22-25 \mathrm{kHz}$ for $20 \mathrm{~min}$. The catalysts loading was 1.5 and $2 \mathrm{mg} / \mathrm{cm}^{2}$ for the cathode and anode electrocatalysts, respectively. MEAs were formed with the use of Nafion ${ }^{\circledR} 117$ membrane as a solid polymer electrolyte and the prepared electrodes. The anode and cathode and the membrane dividing them were clamped in a titanium laboratory cell composed of two temperaturecontrolled semi-cells [28]. The formation of MEAs was carried out directly in a test laboratory cell after assembling and allowed to stand at $90^{\circ} \mathrm{C}$ without loading for $2 \mathrm{~h}$ [27].

When testing MEAs, the supply of a reagent (deionized water) and the removal of a reaction product (oxygen) on the anode in a laboratory cell was performed by the "gas lift" method (experimental testbench is schematized in Fig. 1). The cathode reaction reagent (air with a relative humidity of 50\%) was blown through the cathode chamber at a flow rate of $0.1-$ $0.5 \mathrm{~L} / \mathrm{min}$ and to remove the water representing an ORR product and the water transferred from the anode chamber filled with water due to electroosmosis. Current-voltage polarization curves (IV curves) of the oxygen pump were measured in a potentiostatic stagewise regime within a range of voltages from 0.45 to $1.4 \mathrm{~V}$. Transition to the following voltage value was carried out only after attaining the steady-state current at a given voltage (as a rule, for 15-20 min).

The experimental IV curves of the oxygen pump were processed with the use of a simple model, which provide the separation of polarization, ohmic, and diffusion losses and is frequently used to analyze the IV curves of SPE fuel cells and water electrolyzers [29-31] and, in the case of an oxygen pump, is expressed by the equation

$$
U_{\mathrm{U} \_\mathrm{OP}}=E^{0}+\eta_{\mathrm{act}}+i R_{\mathrm{tot}}+\eta_{\mathrm{conc}},
$$

where $U_{\mathrm{U}-\mathrm{OP}}$ is the cell voltage, $\mathrm{V} ; E^{0}$ is the equilibrium potential, $\mathrm{B} ; \eta_{\text {act }}$ is the electrochemical MEA voltage losses, $\mathrm{V} ; \eta_{\text {conc }}$ is the concentration losses, $\mathrm{V} ; i$ is the current density, $\mathrm{A} / \mathrm{cm}^{2}$; and $R_{\text {tot }}$ is the total OP resistance, $\Omega \mathrm{cm}^{2}$. The equilibrium potential $E^{0}$ was calculated by the Nernst equation [32]. The anode and cathode were combined into a single effective electrode, and the electrochemical losses $\eta_{\text {act }}$ of a fuel cell were calculated by the Tafel equation [30]

$$
\eta_{\text {act }}=\frac{2.303 R T}{\alpha F} \log \left(\frac{i}{i_{0}}\right),
$$

where $\alpha$ is the effective transfer coefficient with correction for the number of electrons transferred during

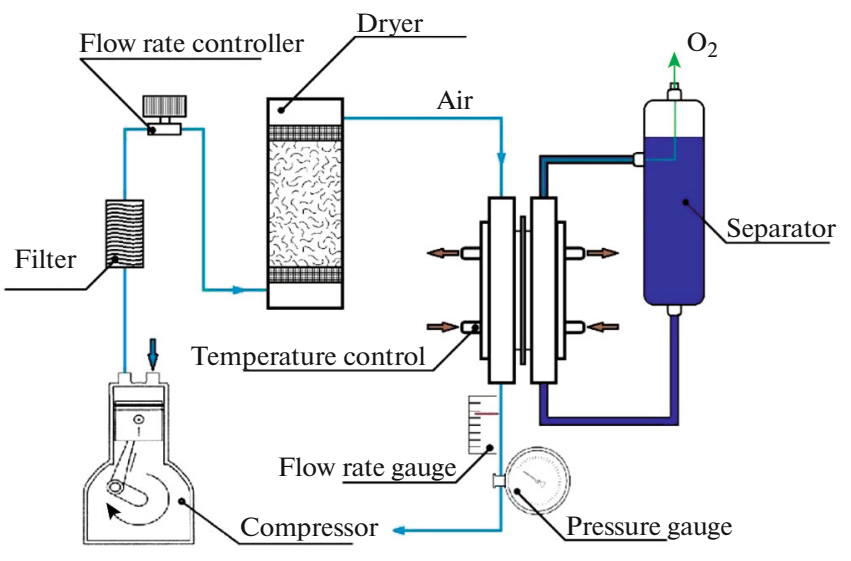

Fig. 1. (Color online) Scheme of the experimental testbench for studying the oxygen pump characteristics.

the rate-determing step of the slowest reaction, and $i_{0}$ is the exchange current density, $\mathrm{A} / \mathrm{cm}^{2}$. The voltage losses due to the oxygen transport limitations to the active sites of the cathode electrocatalyst were determined through the limiting current [31] by the equation

$$
\eta_{\mathrm{conc}}=c \ln \left(\frac{i_{L}}{i_{L}-i}\right)
$$

where $c$ is the constant characterizing the effect of oxygen transport limitations on the ORR thermodynamics and kinetics, $\mathrm{V}$; and $i_{\mathrm{L}}$ is the limiting current, $\mathrm{A} / \mathrm{cm}^{2}$.

\section{RESULTS AND DISCUSSION}

The results of studying the effect produced by the operational parameters of a SPE oxygen pump (air temperature, flow rate, and pressure on the cathode) are given for a membrane electrode assembly based on the cathode catalyst of the most advantageous composition, i.e., $\mathrm{Pt}^{40} / \mathrm{C}^{10}$. The effect of the PTFE content in the cathode catalyst support is analyzed at the end of this paper.

The SPE oxygen pump IV curves recorded at different temperatures are plotted in Fig. 2. Similarly to SPE water electrolyzers, the proton-exchange membranes used in an oxygen pump must be thicker (e.g., such as Nafion ${ }^{\circledR} 117$ of $\sim 180 \mu \mathrm{m}$ in thickness) than the membranes used in fuel cells (with a thickness of $50 \mu \mathrm{m}$ and lower). This is due to the possibility to use higher working temperatures (up to $80^{\circ} \mathrm{C}$ ) [34] and also to decrease the atmospheric nitrogen diffusion rate and decelerate the anode-to-cathode transport of water.

The temperature effect on the IV curves behaviour in the case of both a waver electrolyzer and an oxygen pump is associated first of all with a decrease in the cathode and anode reaction overpotential (this is 

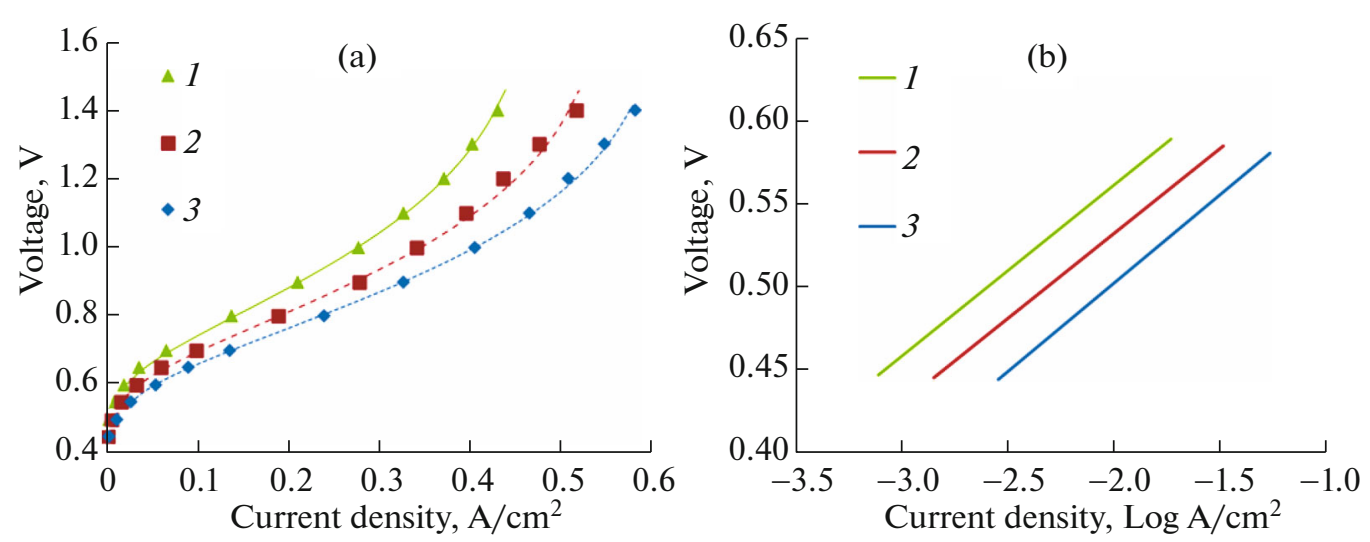

Fig. 2. (Color online) IV curves of the oxygen pump at different temperatures of (1) 40, (2) 60 , and (3) $80^{\circ} \mathrm{C}$ for cathode catalyst $\mathrm{Pt}^{40} / \mathrm{C}^{10}$ at an air flow rate of $0.5 \mathrm{~L} / \mathrm{min}$.

especially appreciable in the region of low current densities below $0.1 \mathrm{~A} / \mathrm{cm}^{2}$ ) and in the ohmic MEA resistance (which generally depends on the proton conductivity of a membrane [35], the electron and proton conductivity of catalytic layers [36], and the contact resistances between the MEA components [37]), which is exhibited as a decrease in the slope of the linear IV curve region within a range of current densities of $0.1-0.3 \mathrm{~A} / \mathrm{cm}^{2}$.

The oxygen pump voltage, at which the oxygen concentration process begins to occur at an appreciable rate, is $\sim 0.45-0.5 \mathrm{~V}$, i.e., close to the literature value of $0.53 \mathrm{~V}[16]$.

The IV curve of the oxygen pump (Fig. 2a) has several characteristic regions. In the regions of low current densities (usually below $0.07-0.1 \mathrm{~A} / \mathrm{cm}^{2}$ [27, 34 , $38]$ ), the kinetic losses due to anode and cathode polarization predominate in the value of voltage. When the current density grows, the transition to the linear IV curve region with predominance of ohmic voltage losses is observed. A further nonlinear increase in the voltage at current densities above $0.3 \mathrm{~A} / \mathrm{cm}^{2}$ seems to be due to oxygen transport limitations and a decrease in the oxygen concentration (partial pressure) in the active cathode zone.

The Tafel slope of the IV curve of the Pt/Vulcan $\mathrm{XC}-72$ and Ir black based MEAs (Fig. 2b) in the region of low current densities (below $0.1 \mathrm{~A} / \mathrm{cm}^{2}$ ) incorporates both the oxygen reduction and oxygen evolution reactions [34, 38] and attains $\sim 102-$ $107 \mathrm{mV} / \mathrm{dec}$. The obtained values are quite well substantiated. According to the literature data, the oxygen evolution reaction on amorphous Ir oxides (formed in the anode active layer based on Ir black [39] due to metallic Ir oxidation) occurs at a high rate with participation of activated oxygen atoms from the crystal lattice $[40,41]$ and, in this case, the Tafel slope of this reaction is $\sim 38-45 \mathrm{mV} / \mathrm{dec}$ [42-44]. The Tafel slope of the oxygen reduction reaction occurring at low current densities by the mechanism, which is typical for $\mathrm{Pt}$ and incorporates the transfer of the first electron as a rate-determing step, is $\sim 60-70 \mathrm{mV} / \mathrm{dec}$ [45]. It can be seen from the results shown in Fig. 2a that an increase in the temperature almost has no effect on the reaction mechanism, but makes it possible to elevate the rate of electrochemical reactions [46] and decrease the cell resistance generally, due to an increase in the proton conductivity of a membrane [47]. In particular, when the oxygen pump temperature is increased from 40 to $80^{\circ} \mathrm{C}$, the cell resistance is decreased from 0.3 to $0.23 \Omega \mathrm{cm}^{2}$.

An increase in the working temperature leads to a shift in the limiting current density towards higher values from $0.487 \mathrm{~A} / \mathrm{cm}^{2}$ at $40^{\circ} \mathrm{C}$ to $0.63 \mathrm{~A} / \mathrm{cm}^{2}$, being in good agreement with the data [4]. This seems to be provoked by the acceleration of oxygen diffusion in the active layer and a shift in cell water balance towards a lower humidity in the active cathode layer due to an increase in the moisture capacity of the leaving air.

The results of studying the effect of the air flow rate (excess ratio) on the IV curve of the oxygen pump are shown in Fig. 3.

An increase in the flow rate of air supplied to the cathode (Fig. 3) promotes the faster removal of excess moisture from the pores of the gas diffusion and electrocatalytic layers of the cathode to prevent its flooding. It can be seen from the results shown in Fig. 3 that an increase in the air flow rate has an essential effect on the IV curve of the oxygen pump: at air flow rates ranges within $0.3-0.5 \mathrm{~L} / \mathrm{min}$, IV curve sustains changes only in the region of high current densities, where the losses associated with oxygen transport to the active sites of cathode and its flooding with water are predominant, and the limiting current grows from 


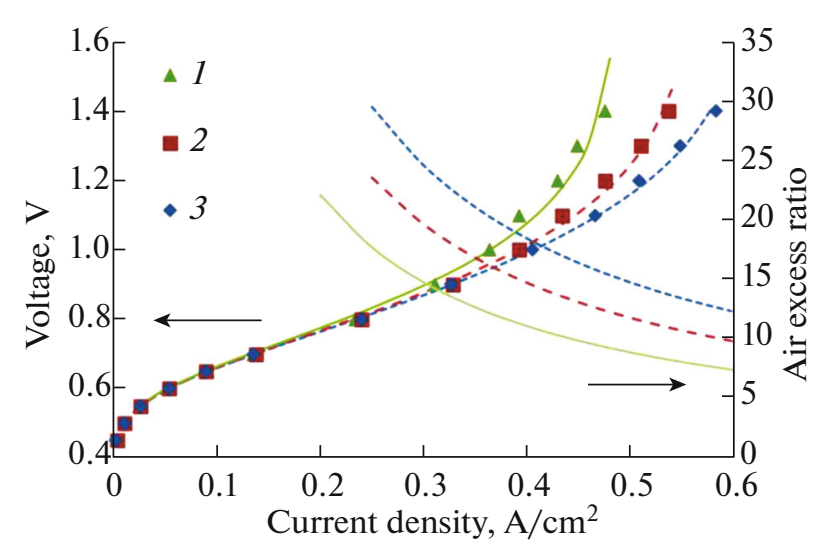

Fig. 3. (Color online) IV curves of the oxygen pump at different air flow rates of (1) 0.3, (2) 0.4 , and (3) $0.5 \mathrm{~L} / \mathrm{min}$ for cathode catalyst $\mathrm{Pt}^{40} / \mathrm{C}^{10}$ at a temperature of $80^{\circ} \mathrm{C}$.

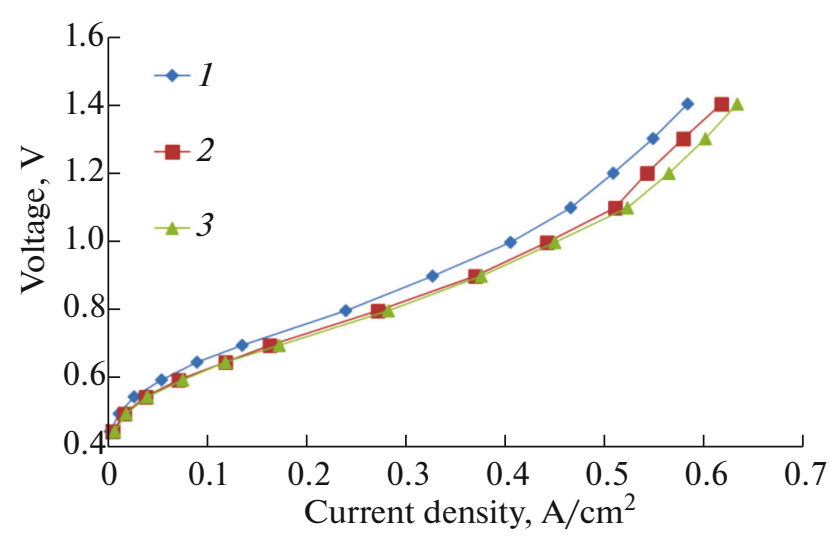

Fig. 4. (Color online) IV curves of the oxygen pump at different air pressures on the cathode of (1) 0.1 , (2) 0.2 , and (3) $0.3 \mathrm{MPa}$ for cathode catalyst $\mathrm{Pt}^{40} / \mathrm{C}^{10}$ at an air flow rate of $0.5 \mathrm{~L} / \mathrm{min}$ and a temperature of $80^{\circ} \mathrm{C}$.

0.488 to $0.63 \mathrm{~A} / \mathrm{cm}^{2}$. It can also be presumed that a further increase in the air flow rate will make it possible to elevate the limiting current density and enhance the oxygen pump performance in linear region of its IV curve (actually, the working range of current densities) to higher values typical for SPE electrolyzers, i.e., to $1 \mathrm{~A} / \mathrm{cm}^{2}$ and higher $[4,16]$. On the other hand, an increase in the air flow rate will be limited by a certain limiting value for a given composition of the electrocatalytic cathode layer such that this will lead to local layer overdrying with an abrupt increase in resistance. Hence, the operation regime of the SPE oxygen pump with a specified MEA composition requires further optimization within a broader range of air flow rates, but this has turned out to be technologically impossible in this study.

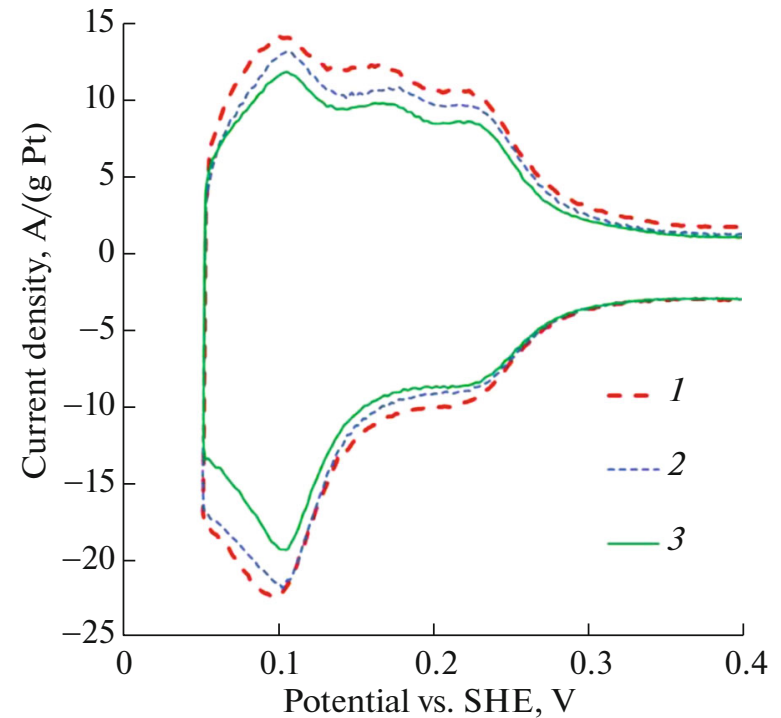

Fig. 5. (Color online) Fragments of cyclic voltammograms measured for different catalysts (1) $\mathrm{Pt}^{40} / \mathrm{C}$, (2) $\mathrm{Pt}^{40} / \mathrm{C}^{5}$, and (3) $\mathrm{Pt}^{40} / \mathrm{C}^{10}$ in a $0.5 \mathrm{M} \mathrm{H}_{2} \mathrm{SO}_{4}$ solution at a temperature of $25^{\circ} \mathrm{C}$ and a potential sweep rate of $20 \mathrm{mV} / \mathrm{s}$.

The results of studying the effect of the air pressure on the cathode on the IV curves of the SPE oxygen pump are shown in Fig. 4. It can be seen from the presented results that the effect of the air pressure on the oxygen pump IV curve has is limited and is generally expressed as the acceleration of cathode reaction kinetics due to an increase in concentration and the facilitation of oxygen access to active catalyst sites and a decrease in the partial oxygen pressure drop (appearing due to the reaction) between the inlet and outlet with a resulting slight decrease in the cell voltage throughout the entire range of current densities $[48,49]$. However, when the pressure grows from 0.2 to $0.3 \mathrm{MPa}$, its effect proves to be negligible.

Improving the transport properties of the cathode electrolytic layer towards faster moisture removal, it is possible to increase the limiting current and enlarge the working range of the SPE oxygen pump. The introduction of PTFE particles into the cathode catalytic layer promotes the formation of a system of channels, which enable the efficient removal of excessive moisture from the layer [31, 50] with more efficient oxygen transport to active catalyst sites [51, 52]. In the submitted work, cathode electrocatalysts were synthesized on the basis of carbon black modified with PTFE particles as a support.

Some fragments of the cyclic voltammograms of synthesized electrocatalysts $\mathrm{Pt}^{40} / \mathrm{C}, \mathrm{Pt}^{40} / \mathrm{C}^{5}$, and $\mathrm{Pt}^{40} / \mathrm{C}^{10}$ are shown in Fig. 5 and were used to estimate their EASA [10, 24]. The plotted curves demonstrate pronounced hydrogen adsorption/desorption peaks, 
Table 1. Characteristics of carbon supports and catalysts on their basis with different PTFE content

\begin{tabular}{l|c|c}
\hline \multicolumn{1}{c|}{ Catalyst } & $\begin{array}{c}\text { Support specific surface area measured } \\
\text { by nitrogen adsorption, } \mathrm{m}^{2} / \mathrm{g}\end{array}$ & Catalyst EASA, $\mathrm{m}^{2} /(\mathrm{g} \mathrm{Pt})$ \\
\hline $\mathrm{Pt}^{40} / \mathrm{C}$ & 230 & 52.5 \\
$\mathrm{Pt}^{40} / \mathrm{C}^{5}$ & 208 & 48.7 \\
$\mathrm{Pt}^{40} / \mathrm{C}^{10}$ & 171 & 43.3 \\
$\mathrm{Pt}^{40} / \mathrm{C}^{15}$ & 138 & 37.4 \\
\hline
\end{tabular}

which appear in the region of potentials of $\sim 0.05-$ $0.40 \mathrm{~V}$ with respect to a standard hydrogen electrode (SHE) as typical for the catalysts based on Pt nanoparticles [53], represent the charge spent on $\mathrm{H}_{2}$ adsorption/desorption on the monolayer, and are used to determine the EASA of electrocatalysts. The shape of these curves indicates that the introduction of PTFE particles into the support has no effect on the polycrystalline structure of Pt nanoparticles [53].

The specific surface area of supports and the EASA of synthesized catalysts with different PTFE concentrations are given in Table 1.

The preliminary precipitation of PTFE particles onto the carbon black surface leads to an appreciable decrease in its BET specific surface area, and the EASA of the electrocatalysts based on the mentioned supports decreases not so fast with increasing PTFE content (Table 1). This may be explained by that the number of Pt particle nuclei on the surface of a support at a moderate PTFE concentration (below 5$10 \mathrm{wt} \%$ ) remains sufficient for the formation of particles with an optimal morphology, and the degree of $\mathrm{Pt}$ utilization slightly grows due to the acceleration of diffusion in the catalytic layer [54].

The results of studying the performance of the SPE oxygen pump with the cathode catalysts based on the
PTFE modified carbon support are shown in Fig. 6 . The submitted results indicate that the application of a modified support has an essential effect on the oxygen pump IV curve. In particular, the modification of the support with 5 and $10 \mathrm{wt} \%$ of PTFE has provided an increase in the limiting current from 0.58 to 0.605 and $0.63 \mathrm{~A} / \mathrm{cm}^{2}$, respectively. In this case, the Tafel slope of all the studied MEAs lies within a narrow range from 104 to $109 \mathrm{mV} / \mathrm{dec}$, with argues for a negligible effect of PTFE in the support on the ORR mechanism. The dependence of the limiting current on the PTFE content in the cathode catalyst support is shown in Fig. $6 \mathrm{~b}$ and passes through a maximum corresponding to the optimal value of $10 \mathrm{wt} \%$. The modification of the carbon support with the optimal PTFE content essentially improves water transport in the cathode electrocatalytic layer, prevents its premature flooding, facilitates oxygen access to active catalyst sites, and increases the degree of Pt utilization [31, 50 , 51]. A further increase in the PTFE content leads to the growth of $\mathrm{Pt}$ nanoparticles in size, a decrease in the catalyst EASA, and an appreciable decrease in the proton conductivity of the catalytic layer (due to a decrease in the proton-conducting polymer content [55]) and seems to worsen the oxygen pump IV curve.

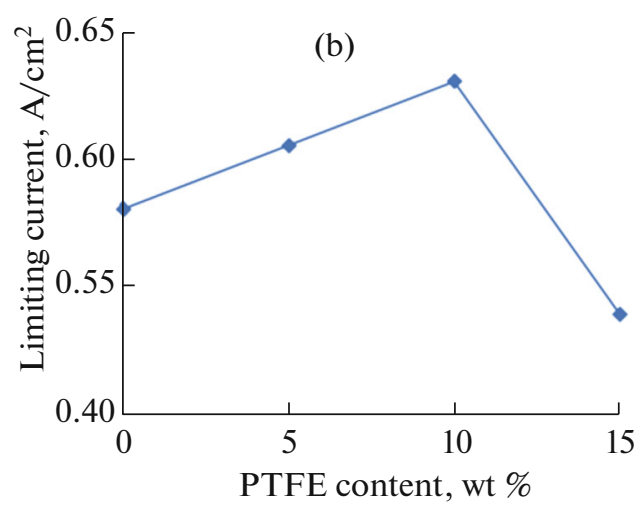

Fig. 6. (Color online) IV curves of the oxygen pump at different PTFE content on the cathode for cathode catalyst $\mathrm{Pt}^{40} / \mathrm{C}^{X}$, where $X$ is (1) 0, (2) 5 , (3) 10 , or (4) 15 , at an air flow rate of $0.5 \mathrm{~L} / \mathrm{min}$ and a temperature of $80^{\circ} \mathrm{C}$. 


\section{CONCLUSIONS}

The effect produced by the hydrophobization of a carbon support on the endurance of a cathode catalytic layer to flooding and the effect of the working temperature, air flow rate, and pressure on the performance of a SPE oxygen pump have been considered. It has been shown that the air flow rate (excess ratio) has an essential effect on the limiting current (which characterizes the appearance of limitations for mass transfer in the catalytic layer in the case of its flooding), thus make it possible to enlarge the working range of current densities and essentially decrease the energy consumption in oxygen production. However, this requires the air flow rate to be optimized within a broader range of values. On the contrary, the air pressure has a limited effect on the SPE oxygen pump performance. The introduction of PTFE into the carbon support is an efficient mean against the premature flooding of the cathode catalytic layer and makes it possible to increase the limiting current and enlarge the working range of current densities for the SPE oxygen pump, though this leads to an essential decrease in the specific surface area accessible for the formation of active nanoparticles on the support and the EASA of the respective catalysts on its basis. On the whole, the energy consumption in oxygen production are 3.4$4.7(\mathrm{~kW} \mathrm{~h}) /\left(\mathrm{STPm}^{3} \mathrm{O}_{2}\right)$ at a current density of $0.15-$ $0.4 \mathrm{~A} / \mathrm{cm}^{2}$, being $1.5-2$ times lower as compared to an SPE electrolyzer.

\section{FUNDING}

This study was financially supported by the President of the Russian Federation (scholarship no. SP-1764.2019.1) and the National Research Center "Kurchatov Institute" (directive no. 1919 from 25.09.2020, the subprogram no. 6).

\section{REFERENCES}

1. O. Z. Sharaf and M. F. Orhan, Renewable Sustainable Energy Rev. 32, 810 (2014). https://doi.org/10.1016/j.rser.2014.01.012

2. K. Ayers, Curr. Opin. Electrochem. 18, 9 (2019). https://doi.org/10.1016/j.coelec.2019.08.008

3. B. Eladeb, C. Bonnet, E. Favre, and F. Lapicque, J. Electrochem. Sci. Eng. 2, 211 (2012). https://doi.org/10.5599/jese.2012.0016

4. A. A. Kalinnikov, S. V. Ostrovskii, V. I. Porembskii, A. S. Pushkarev, and V. N. Fateev, Russ. J. Appl. Chem. 91, 925 (2018).

5. S. A. Grigoriev, I. G. Shtatniy, P. Millet, et al., Int. J. Hydrogen Energy 36, 4148 (2011). https://doi.org/10.1016/j.ijhydene.2010.07.012

6. D. Li, R. Qi, and L.-Z. Zhang, Int. J. Hydrogen Energy 44, 19533 (2019).

https://doi.org/10.1016/j.ijhydene.2019.06.011

7. F. Okada, K. Nagashima, and T. Kobayashi, Electrochim. Acta 294, 391 (2019).

https://doi.org/10.1016/j.electacta.2018.10.055
8. A. S. Pushkarev, I. V. Pushkareva, and S. A. Grigor'ev, Zh. Prikl. Khim. 89, 857 (2016).

9. H. Ju, S. Badwal, and S. Giddey, Appl. Energy 231, 502 (2018). https://doi.org/10.1016/j.apenergy.2018.09.125

10. A. Pushkarev, I. Pushkareva, N. Ivanova, et al., Catalysts 9, 271 (2019). https://doi.org/10.3390/catal9030271

11. A. Smith and J. Klosek, Fuel Process. Technol. 70, 115 (2001). https://doi.org/10.1016/S0378-3820(01)00131-X

12. C. C. Lai, T. P. Shih, W. C. Ko, et al., Int. J. Antimicrob. Agents 55, 105924 (2020). .

https://doi.org/10.1016/j.ijantimicag.2020.105924

13. M. Carmo, D. L. Fritz, J. Mergel, and D. Stolten, Int. J. Hydrogen Energy 38, 4901 (2013). https://doi.org/10.1016/j.ijhydene.2013.01.151

14. H. Ito, T. Maeda, A. Nakano, and H. Takenaka, Int. J. Hydrogen Energy 36, 10527 (2011). https://doi.org/10.1016/j.ijhydene.2011.05.127

15. S. A. Grigoriev, V. I. Porembskiy, S. V. Korobtsev, et al., Int. J. Hydrogen Energy 36, 2721 (2011). https://doi.org/10.1016/j.ijhydene.2010.03.058

16. S. Giddey, F. T. Ciacchi, and S. P. S. Badwal, J. Membr. Sci. 346, 227 (2010). https://doi.org/10.1016/j.memsci.2009.09.042

17. Y. Wang, D. F. Ruiz Diaz, K. S. Chen, et al., Mater. Today 32, $178(2020)$. https://doi.org/10.1016/j.mattod.2019.06.005

18. N. E. Cipollini, R. J. Roy, and C. Eldridge, "High-differential-pressure water electrolysis cell and method of operation," US Patent No. 20110198232A1 (2011).

19. T. Banaszkiewicz, M. Chorowski, and W. Gizicki, Energy Proc. 51, 127 (2014). https://doi.org/10.1016/j.egypro.2014.07.014

20. W. Schmittinger and A. Vahidi, J. Power Sources 180, 1 (2008). https://doi.org/10.1016/j.jpowsour.2008.01.070

21. G. Xie and T. Okada, J. Electrochem. Soc. 142, 3057 (1995). https://doi.org/10.1149/1.2048686

22. I. E. Baranov, V. I. Porembskii, E. K. Lyutikova, et al., Chem. Probl. 17, 489 (2019). https://doi.org/10.32737/2221-8688-2019-4-489-499

23. S. Grigoriev, V. Fateev, A. Pushkarev, et al., Materials 11, 1405 (2018). https://doi.org/10.3390/ma11081405

24. D. D. Spasov, N. A. Ivanova, A. S. Pushkarev, et al., Catalysts 9, 803 (2019). https://doi.org/10.3390/catal9100803

25. I. V. Pushkareva, A. S. Pushkarev, S. A. Grigor'ev, E. K. Lyutikova, S. V. Akel'kina, M. A. Osina, E. P. Slavcheva, and V. N. Fateev, Russ. J. Appl. Chem. 89, 2109 (2016).

26. V. Fateev, O. Alekseeva, E. Lutikova, et al., Int. J. Hydrogen Energy 41, 10515 (2016). https://doi.org/10.1016/j.ijhydene.2016.04.192

27. A. S. Pushkarev, M. A. Solovyev, S. A. Grigoriev, et al., Int. J. Hydrogen Energy (2020). https://doi.org/10.1016/j.ijhydene.2020.02.098 
28. R. Valiollahi, M. Vagin, V. Gueskine, et al., Sustain. Energy Fuels 3, 3387 (2019). https://doi.org/10.1039/C9SE00687G

29. C. Rakousky, U. Reimer, K. Wippermann, et al., J. Power Sources 326, 120 (2016). https://doi.org/10.1016/j.jpowsour.2016.06.082

30. D. Bezmalinovic, B. Simic, and F. Barbir, J. Power Sources 294, 82 (2015). https://doi.org/10.1016/j.jpowsour.2015.06.047

31. G. S. Avcioglu, B. Ficicilar, A. Bayrakceken, and I. Eroglu, Int. J. Hydrogen Energy 40, 7720 (2015). https://doi.org/10.1016/j.ijhydene.2015.02.004

32. V. B. Avakov, V. A. Bogdanovskaya, A. V. Kapustin, O. V. Korchagin, A. V. Kuzov, I. K. Landgraf, M. M. Stankevich, and M. R. Tarasevich, Russ. J. Electrochem. 51, 570 (2015).

33. S. Haji, Renewable Energy 36, 451 (2011). https://doi.org/10.1016/j.renene.2010.07.007

34. H. Ito, T. Maeda, A. Nakano, et al., Electrochim. Acta 100, 242 (2013). https://doi.org/10.1016/j.electacta.2012.05.068

35. J. Mališ, P. Mazúr, M. Paidar, et al., Int. J. Hydrogen Energy 41, 2177 (2016). https://doi.org/10.1016/j.ijhydene.2015.11.102

36. U. Babic, T. J. Schmidt, and L. Gubler, J. Electrochem. Soc. 165 (15), J3016 (2018). https://doi.org/10.1149/2.0031815jes

37. P. Lettenmeier, S. Kolb, F. Burggraf, et al., J. Power Sources 311, 153 (2016). https://doi.org/10.1016/j.jpowsour.2016.01.100

38. S. Siracusano, V. Baglio, A. di Blasi, et al., Int. J. Hydrogen Energy 35, 5558 (2010). https://doi.org/10.1016/j.ijhydene.2010.03.102

39. S. Siracusano, V. Baglio, S. A. Grigoriev, et al., J. Power Sources 366, 105 (2017). https://doi.org/10.1016/j.jpowsour.2017.09.020

40. S. Fierro, T. Nagel, H. Baltruschat, and C. Comninellis, Electrochem. Commun. 9, 1969 (2007). https://doi.org/10.1016/j.elecom.2007.05.008

41. S. Geiger, O. Kasian, M. Ledendecker, et al., Nat. Catal. 1, 508 (2018).

https://doi.org/10.1038/s41929-018-0085-6
42. P. Lettenmeier, L. Wang, U. Golla-Schindler, et al., Angew. Chem. Int. Ed. 55, 742 (2016). https://doi.org/10.1002/anie.201507626

43. A. S. Pushkarev, I. V. Pushkareva, S. P. Du Preez, et al., Chem. Probl. 17, 9 (2019). https://doi.org/10.32737/2221-8688-2019-1-9-15

44. D. F. Abbott, D. Lebedev, K. Waltar, et al., Chem. Mater. 28, 6591 (2016). https://doi.org/10.1021/acs.chemmater.6b02625

45. V. A. Bogdanovskaya, M. R. Tarasevich, and O. V. Lozovaya, Russ. J. Electrochem. 47, 846 (2011).

46. A. Parthasarathy, S. Srinivasan, J. A. Appleby, and C. R. Martin, J. Electrochem. Soc. 139, 2530 (1992). https://doi.org/10.1149/1.2221258

47. J. van der Merwe, K. Uren, G. van Schoor, and D. Bessarabov, Int. J. Hydrogen Energy 39, 14212 (2014).

https://doi.org/10.1016/j.ijhydene.2014.02.096

48. M. Amirinejad, S. Rowshanzamir, and M. H. Eikani, J. Power Sources 161, 872 (2006). https://doi.org/10.1016/j.jpowsour.2006.04.144

49. A. J.-J. Kadjo, P. Brault, A. Caillard, et al., J. Power Sources 172, 613 (2007). https://doi.org/10.1016/j.jpowsour.2007.05.019

50. G. S. Avcioglu, B. Ficicilar, and I. Eroglu, Int. J. Hydrogen Energy (2018). https://doi.org/10.1016/j.ijhydene.2018.03.045

51. Z. Wan, S. Liu, Q. Zhong, et al., Int. J. Hydrogen Energy 43, 7456 (2018). https://doi.org/10.1016/j.ijhydene.2018.01.091

52. M. Wang, M. Chen, Z. Yang, et al., Energy Convers. Manag. 191, 132 (2019). https://doi.org/10.1016/j.enconman.2019.04.014

53. H. A. Gasteiger, S. S. Kocha, B. Sompalli, and F. T. Wagner, Appl. Catal. B 56, 9 (2005). https://doi.org/10.1016/j.apcatb.2004.06.021

54. W. Song, H. Yu, L. Hao, et al., Solid State Ionics. 181, 453 (2010). https://doi.org/10.1016/j.ssi.2010.01.022

55. I. E. Baranov, I. I. Nikolaev, A. S. Pushkarev, et al., Int. J. Electrochem. Sci. 13, 8673 (2018). https://doi.org/10.20964/2018.09.48

Translated by E. Glushachenkova 